JIOM Nepal. Volume 41 Number 3. December 2019, page 17-23.

\title{
Profile and Outcome of Patients Admitted to Pediatric Intensive Care Unit at a General Referral Hospital
}

\author{
Arun K Sharma, Binay Gurung
}

Department of Pediatrics, Maharajgunj Medical Campus, Tribhuvan University Teaching Hospital, Institute of Medicine, Kathmandu

\section{Corresponding author:}

Arun Kumar Sharma, MBBS, MD

Department of Pediatrics, Maharajgunj Medical Campus, Tribhuvan University Teaching Hospital, Institute of Medicine, Kathmandu

Email: docarunsharma@iom.edu.np

Submitted : November 7, 2019

Accepted : December 8, 2019

\begin{abstract}
Introduction

Nepal has made substantial progress in child health primarily through preventive care. There is an increasing need for critical care services across the country which is highly resource-intensive. Periodic data of critical care admissions help plan the utilization of scarce resources in a low-income country like Nepal. This study aimed to analyze the epidemiologic patterns of critically ill pediatric patients admitted to the pediatric intensive care unit (PICU).
\end{abstract}

\section{Methods}

This descriptive study of all children admitted to PICU at Tribhuvan University Teaching Hospital for 18 months between October 2017 and April 2019 was conducted by a retrospective review of hospital records. Demographic data, etiologies of PICU admissions and outcomes of children admitted to the PICU were analyzed.

\section{Results}

PICU admitted 413 children during the study duration from all over the country. Children under the age of 2 years (36\%) were admitted in the largest number and boys outnumbered girls (65.1\%). Respiratory illnesses, neurosurgical and neurological problems, infectious disorders and airway foreign bodies were the most common etiologies for admission. The average length of ICU stay was around 4.4 days. Almost one-third of patients required circulatory and respiratory support. At the time of exit from PICU, 14.3\% of patients died; $4.3 \%$ patients had opted for withdrawal of life support or decided to leave hospital against medical advice.

\section{Conclusion}

Patients with diverse etiologies were admitted to ICU from all over the country. A similar analysis from PICUs across the country can serve as the basis for development of newer intensive care facilities in the country, developing dedicated protocols for critical care and redistributing the ICUs' available resources for optimal efficiency.

Keywords: Critical illness, intensive care unit, outcome, PICU, profile

\section{INTRODUCTION}

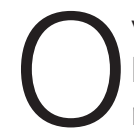

ver the last few decades, Nepal had a leaping success towards the attainment of millennium development goals in reducing child mortality. ${ }^{1,2}$ Much of this has been achieved through preventive health services, but improved access to healthcare and delivery of service has also contributed to this achievement. ${ }^{3}$ Health seeking behavior has also changed over the years and an increasing number of children are being referred for intensive care services. ${ }^{4}$

Intensive care service for children is a lifesaving care for potentially recoverable life-threatening conditions that can benefit from better 
Table 1. Demographics and background characteristics of patients admitted to PICU $(n=413)$

\begin{tabular}{|c|c|c|c|}
\hline Patient characteristics $\quad(N=413)$ & Male & Female & Total \\
\hline $\begin{array}{l}\text { Age group } \\
<6 \text { months } \\
6 \text { months- } 1 \text { year } \\
1-2 \text { years } \\
2-5 \text { years } \\
5-10 \text { years } \\
>10 \text { years }\end{array}$ & $\begin{array}{l}61(14.80 \%) \\
26(6.30 \%) \\
41(9.90 \%) \\
46(11.10 \%) \\
35(8.50 \%) \\
60(14.50 \%)\end{array}$ & $\begin{array}{l}25(6.10 \%) \\
15(3.60 \%) \\
18(4.40 \%) \\
18(4.40 \%) \\
20(4.80 \%) \\
48(11.60 \%)\end{array}$ & $\begin{array}{l}86(20.80 \%) \\
41(9.90 \%) \\
59(15.30 \%) \\
64(15.50 \%) \\
55(13.30 \%) \\
108(26.20 \%)\end{array}$ \\
\hline Gender & $269(65.1 \%)$ & $144(34.9 \%)$ & $413(100.0 \%)$ \\
\hline $\begin{array}{l}\text { Socioeconomic status } \\
\text { (Modified Kuppuswamy Scale) } \\
\text { Upper class } \\
\text { Upper middle class } \\
\text { Lower middle class } \\
\text { Lower upper class } \\
\text { Lower class }\end{array}$ & $\begin{array}{l}- \\
- \\
- \\
-\end{array}$ & $\begin{array}{l}- \\
- \\
- \\
-\end{array}$ & $\begin{array}{l}3.20 \% \\
20.50 \% \\
30.90 \% \\
27.40 \% \\
18.00 \%\end{array}$ \\
\hline $\begin{array}{l}\text { Residence } \\
\text { From Kathmandu } \\
\text { Out of Kathmandu }\end{array}$ & - & - & $\begin{array}{c}95(23.00 \%) \\
318(76.99 \%)\end{array}$ \\
\hline $\begin{array}{l}\text { Portal of entry } \\
\text { Emergency room } \\
\text { Operating room } \\
\text { Pediatric ward } \\
\text { Other wards }\end{array}$ & $\begin{array}{c}110(26.60 \%) \\
78(18.90 \%) \\
63(15.30 \%) \\
18(4.40 \%)\end{array}$ & $\begin{array}{l}52(12.60 \%) \\
41(9.90 \%) \\
39(9.40 \%) \\
12(2.90 \%)\end{array}$ & $\begin{array}{c}162(39.20 \%) \\
119(28.80 \%) \\
102(24.70 \%) \\
30(7.30 \%)\end{array}$ \\
\hline $\begin{array}{l}\text { Primary indication of PICU admission } \\
\text { Respiratory support } \\
\text { Shock } \\
\text { Low GCS } \\
\text { Intensive monitoring/ Post Op }\end{array}$ & $\begin{array}{l}- \\
- \\
- \\
-\end{array}$ & $\begin{array}{l}- \\
- \\
- \\
-\end{array}$ & $\begin{array}{c}130(31.45 \%) \\
75(18.18 \%) \\
69(16.7 \%) \\
139(33.66 \%)\end{array}$ \\
\hline $\begin{array}{l}\text { Primary illness } \\
\text { Respiratory illness } \\
\text { Neurosurgical disorders including brain abscess } \\
\text { Primary Infectious diseases } \\
\text { Neurological disorders } \\
\text { Foreign body bronchus } \\
\text { Cardiac disorders } \\
\text { Renal disorders } \\
\text { ENT disorders } \\
\text { Post major surgery } \\
\text { Gastrointestinal disorders } \\
\text { Hemato-oncological disorders } \\
\text { Poisoning } \\
\text { Endocrine disorders }\end{array}$ & $\begin{array}{l}33(7.99 \%) \\
44(10.65 \%) \\
33(7.99 \%) \\
30(7.26 \%) \\
32(7.75 \%) \\
28(6.90 \%) \\
13(3.15 \%) \\
15(3.63 \%) \\
11(2.66 \%) \\
13(3.15 \%) \\
9(2.18 \%) \\
4(0.97 \%) \\
4(1.00 \%)\end{array}$ & $\begin{array}{l}21(5.08 \%) \\
20(4.84 \%) \\
21(5.08 \%) \\
12(2.91 \%) \\
9(2.18 \%) \\
10(2.50 \%) \\
14(3.39 \%) \\
11(2.66 \%) \\
10(2.42 \%) \\
7(1.69 \%) \\
4(0.97 \%) \\
4(0.97 \%) \\
1(0.20 \%)\end{array}$ & $\begin{array}{l}54(13.08 \%) \\
64(15.50 \%) \\
54(13.08 \%) \\
42(10.17 \%) \\
41(9.93 \%) \\
38(9.30 \%) \\
27(6.54 \%) \\
26(6.30 \%) \\
21(5.08 \%) \\
20(4.84 \%) \\
13(3.15 \%) \\
8(1.94 \%) \\
5(1.20 \%\end{array}$ \\
\hline
\end{tabular}

observation, intensive treatment and technological support that is not available in general wards or high dependency facilities. ${ }^{5}$ Nepal is a lowincome country and has very limited critical care services targeted towards children. ${ }^{6}$ Care of critically ill patients is highly resource-intensive and contributes to a huge economic burden on the health system and the family. ${ }^{7}$ It is therefore important to periodically review the profile and outcome of patients admitted to referral centers to develop the best approaches to reduce the need of referral to intensive care services at huge distances and develop local/regional capacities of intensive or high dependency care. The increasing focus on the quality and safety of medical care also requires this data to be periodically updated to compare and evaluate outcomes across institutions to enhance the quality improvement efforts across 
the country.

Pediatric intensive care unit (PICU) in Tribhuvan University Teaching Hospital (TUTH) located in Kathmandu serves as a major referral center due to multidisciplinary care available at this hospital. The objective of this study was to determine the profile for patients admitted to PICU of TUTH and their outcome that is expected to help policy decisions for the provision of intensive care facilities.

\section{METHODS}

We conducted this descriptive study over one and half year period from mid-October 2017 to mid-April 2019 (1st Kartik 2074 to 32nd Chaitra 2075) among all children admitted to the PICU at TU Teaching Hospital. The PICU at TUTH is an open model ICU with 4 beds and provides care for children between 1 month and 16 years of age. The PICU provides intensive care monitoring, respiratory and circulatory support but doesn't have in-house hemodialysis or hemofiltration/plasmapheresis facility. The PICU admits patients directly from the emergency room, operation theatres or from the general wards.

The data were extracted retrospectively from the hospital records available with the medical records section. All consecutive children admitted to PICU over the aforementioned period were included. Infants under the age of 1 month were not admitted to the PICU and are not a part of the study. Variables were only analyzed if there were no missing data. Data were tabulated and analyzed using frequency and percentage, and nominal data were compared using the $\chi^{2}$ test wherever applicable. SPSS version 17.0 was used for this analysis. 'p' values less than 0.05 were considered significant.

\section{RESULTS}

During the period of the study, 413 patients were admitted to this PICU. Table 1 provides the demographic and background characteristics of the patients admitted to PICU.

The mean age of patients admitted during the study period was 5.6 years (SD: 5.4) with a range of 1 month-18 years. The age and gender distribution of patients admitted to PICU during this period is presented in Table 1 below. Infants under 12 months of age constituted the largest group of children admitted (30.7\%), 61.5\% of all admitted patients were under 5 years of age. More boys $(65.1 \%)$ than girls were admitted to the PICU. Majority of patients arrived from far off distances and belonged to poorer economic groups in the society. Most of them were admitted
Table 2. Requirement of mechanical ventilation and circulatory support $(n=413)$

\begin{tabular}{lc}
\hline \multicolumn{1}{c}{ Patient characteristics } & Number \\
\hline Total patients mechanically & $141(34.1 \%)$ \\
ventilated & \\
Indication of ventilation & \\
Respiratory support & $57(40.4 \%)$ \\
Shock & $12(8.5 \%)$ \\
Post-operative & $46(32.6 \%)$ \\
Low GCS & $26(18.4 \%)$ \\
& \\
Total patients treated for shock & $115(27.8 \%)$ \\
Type of shock & \\
Septic & $76(66.1 \%)$ \\
Hypovolemic & $11(9.56 \%)$ \\
Cardiogenic & $25(21.7 \%)$ \\
Obstructive & $3(2.6 \%)$ \\
Distributive & $0(0 \%)$ \\
\hline
\end{tabular}

for respiratory support or need of intensive hemodynamic monitoring.

Respiratory disorders, infectious illness, neurological illnesses, neurosurgical illnesses and foreign bodies in bronchus were among the most common reasons for PICU admission. The median age of patients admitted with foreign body bronchus was 1.5 years.

Shock requiring inotropic support was managed in $115 / 413(27.85 \%)$ patients and respiratory support in the form of mechanical ventilation was required in $141 / 413$ (34.14\%) of patients. Table 2 outlines the course of patients as indications for the need for mechanical ventilation and different categories of shock managed in children during the period of stay in PICU.

The mean duration of stay was 4.4 days (SD: 6.182 days) with a range of 1-54 days. Table 3 outlines the number of patients admitted to the PICU and their outcome in relation to gender and primary illness. Although majority of patients improved to care, $59(14.28 \%)$ admitted patients died at the time of exit from PICU. Among these children, 48 (11.62\%) died during the course of PICU care while 11 children were declared dead after the withdrawal of life support before their exit from PICU. A total of $18(4.32 \%)$ patients had opted for withdrawal of life support (including mechanical ventilation and/or multiple inotropes for circulatory support) or wanted to leave against medical advice from the hospital. Multi-organ dysfunction syndrome (MODS) and acute respiratory distress syndrome (ARDS) had high mortality rates. Out of 14 (3.3\%) patients managed for ARDS, 7 died. There were $24(5.81 \%)$ patients with MODS and 18 of them 


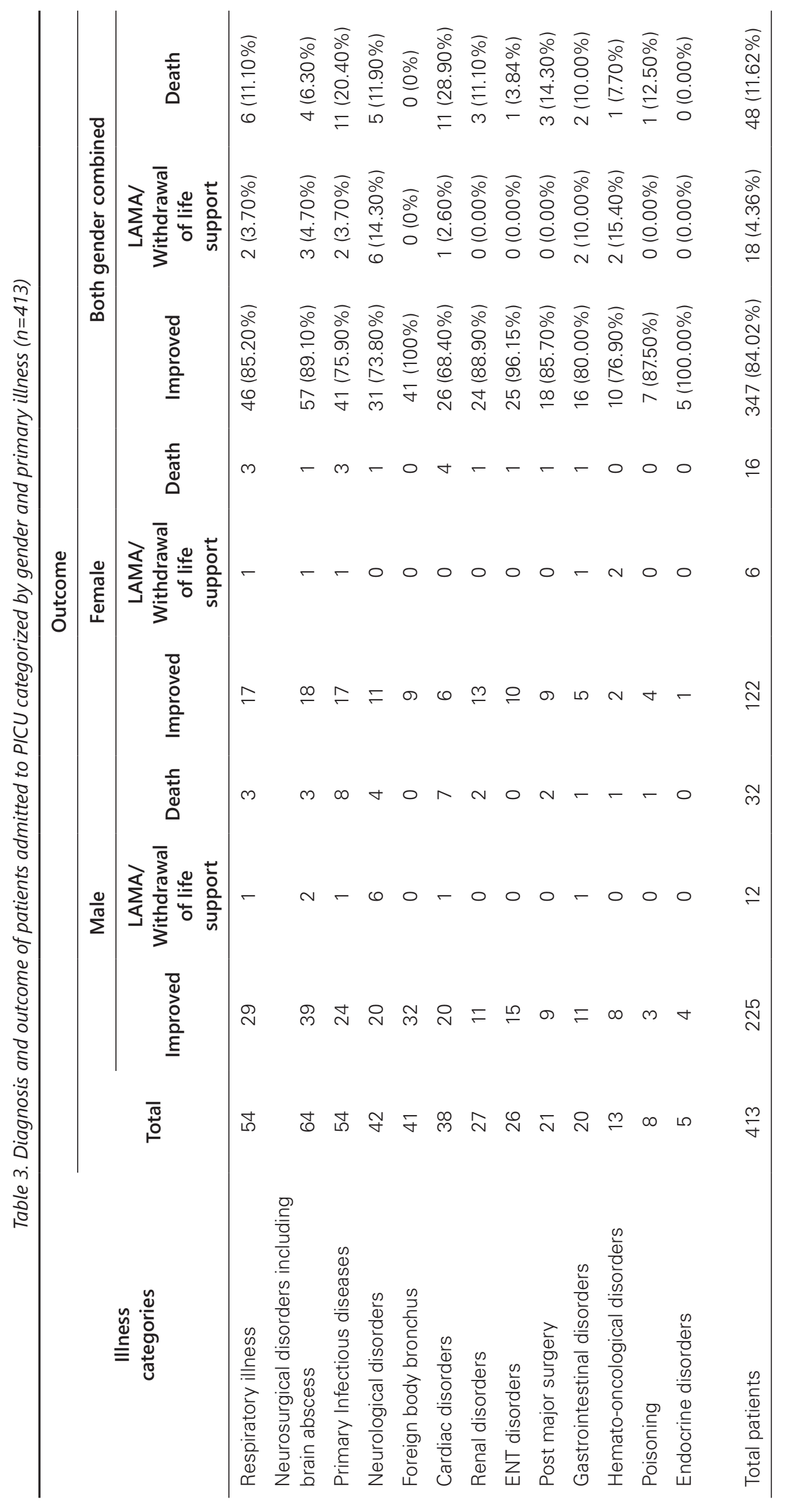


Table 4. Patient characteristics and their relationship to outcome $(n=413)$

\begin{tabular}{|c|c|c|c|}
\hline \multirow[b]{2}{*}{ Patient characteristics $\quad(\mathrm{N}=413)$} & \multicolumn{2}{|c|}{ Outcome } & \multirow[b]{2}{*}{$\mathrm{p}$-value } \\
\hline & $\begin{array}{l}\text { Survived to } \\
\text { PICU discharge }\end{array}$ & Death in PICU & \\
\hline All patients & $354(85.7 \%)$ & $59(14.3 \%)$ & 0.30 \\
\hline Average length of stay & 4.36 (SD 6.1) & 5.25 (SD 6.4) & \\
\hline $\begin{array}{l}\text { Short versus long PICU stay } \\
\text { Short ( }<3 \text { days) stay } \\
\text { Long ( }>3 \text { days) stay }\end{array}$ & $\begin{array}{l}184(68.1 \%) \\
170(53.1 \%)\end{array}$ & $\begin{array}{l}27(6.5 \%) \\
32(7.7 \%)\end{array}$ & 0.22 \\
\hline $\begin{array}{l}\text { Time of death }(n=59) \\
\text { Mortality }<24 \text { hour } \\
\text { Mortality } 24-72 \text { hours } \\
\text { Mortality }>72 \text { hours }\end{array}$ & $\begin{array}{l}- \\
- \\
-\end{array}$ & $\begin{array}{l}22(37.2 \%) \\
14(23.7 \%) \\
23(38.9 \%)\end{array}$ & \\
\hline $\begin{array}{l}\text { Age group } \\
<6 \text { months } \\
6 \text { months- } 1 \text { year } \\
1-2 \text { years } \\
2-5 \text { years } \\
5-10 \text { years } \\
>10 \text { years }\end{array}$ & $\begin{array}{l}71(82.56 \%) \\
37(90.24 \%) \\
55(93.22 \%) \\
54(84.38 \%) \\
49(89.09 \%) \\
88(81.48 \%)\end{array}$ & $\begin{array}{c}15(17.44 \%) \\
4(9.76 \%) \\
4(6.78 \%) \\
10(15.63 \%) \\
6(10.91 \%) \\
20(18.52 \%)\end{array}$ & 0.27 \\
\hline $\begin{array}{l}\text { Gender } \\
\text { Male } \\
\text { Female }\end{array}$ & $\begin{array}{l}230(85.5 \%) \\
124(86.1 \%)\end{array}$ & $\begin{array}{l}39(14.5 \%) \\
20(13.9 \%)\end{array}$ & 0.49 \\
\hline $\begin{array}{l}\text { Portal of entry } \\
\text { Emergency room } \\
\text { Operating room } \\
\text { Pediatric ward } \\
\text { Other wards }\end{array}$ & $\begin{array}{l}130(31.4 \%) \\
113(27.3 \%) \\
83(20.1 \%) \\
28(6.7 \%)\end{array}$ & $\begin{array}{c}32(7.7 \%) \\
6(1.4 \%) \\
19(4.6 \%) \\
2(0.5 \%)\end{array}$ & \\
\hline
\end{tabular}

either died or had withdrawal of life support or left against medical advice.

Table 4 outlines additional outcome in relation to patient characteristics. There were no statistically significant differences in outcome among children of different age groups and among children who stayed in PICU for a shorter or longer duration. Most children (60.9\%) died early within 72 hours of admission. Patients who were treated with mechanical ventilation had mixed outcome. Although $58.9 \%$ of them improved, $30.5 \%$ of them died and $10.6 \%$ had their respiratory support withdrawn. Among children treated for shock, $69.56 \%$ of patients improved.

\section{DISCUSSION}

The pediatric critical care services are still in infancy in Nepal.8,9 Improving national child mortality indicators and improving socioeconomic status in general along with rapid growth of urban population and decreasing family size has created a huge demand for health systems. ${ }^{10}$ This has also translated to increasing demand for pediatric critical care services. During this study period of 18 months, 413 children in different age groups were admitted to PICU at TUTH with diverse diagnoses from all across the country. Respiratory illnesses, neurological and neurosurgical conditions, infectious illnesses and airway foreign bodies were among the five most common conditions requiring admission to PICU. Almost one-third of the patients were treated for shock and mechanically ventilated. Around $14.3 \%$ of patients admitted to the PICU died and $4.3 \%$ of patients requested withdrawal of lifesaving supportive care or left PICU against medical advice.

The concept of pediatric critical care is emerging in Nepal and pediatric intensive care service is a relatively new area of specialty in development. ${ }^{8}$ Infectious illnesses, especially acute respiratory infections and diarrheal illnesses are still important causes of morbidity and mortality in children. Widespread vaccination and health education coupled with changing sociodemographic characteristics of the population has however 
changed the scenario. Compelling needs for services oriented to more critical illnesses is being increasingly recognized across the country.

Critically ill infants, children, and adolescents are admitted to Intensive care services for various diagnostic and therapeutic indications which varies with location, type of ICU service and expertise available for potentially life-threatening illness. ${ }^{11}$ In this study conducted in a general pediatric open care ICU with a small capacity of 4 running beds, patients were admitted with diseases in various organ systems suggesting the need of number of general ICU beds across the country.

We noticed that children younger than 5 years of age were the most vulnerable age group representing the majority of admitted patients to PICU, especially children younger than 2 years. This is in line with similar findings in other reports from the region. ${ }^{12,13}$ Studies performed in neighboring India with similar designs have reported similar findings with infants as the most common age group of children admitted to PICU. ${ }^{14}$ The overall mortality rate in this study was $14.3 \%$. Similar studies from Nepal, India and Pakistan in this region have reported variable mortality rates. Basnet et al and Shah et al reported mortality rates of $26 \%{ }^{12}$ and $12.6 \%^{13}$ in their series in two regions of Nepal whereas rates varying between $4.1 \%$ to $27.34 \%$ have been reported in India ${ }^{14,15}$ and Pakistan ${ }^{16}$. The mortality rate was almost similar across different age groups in the current study. Other studies have identified infants as the most vulnerable group for death in PICU care. ${ }^{14-17}$ Most patients who had serious multi-organ dysfunction during the period died. Similar results have also been reported by other studies in developing countries. ${ }^{17}$ In this study, patients stayed for an average of 4.4 days (SD 6.1) in PICU and the average duration did not differ much between survivors and those who died. Increasingly longer duration of stay in an intensive care unit is common with healthcareassociated infections. ${ }^{18}$ A number of patients in the current series had growth of Acinetobacter in microbiological specimens (results not shown).

Limited data have been published on profile of PICU admission in Nepal. ${ }^{12,13}$ Majority of patients in this study came from far off regions out of the valley. TUTH serves as a referral hospital and some of the services are not available in other areas of the country which explains the high burden of neurosurgical illness and airway foreign bodies removed with rigid bronchoscopy in this series. The epidemiologic profile of patients treated in peripheral ICUs is likely to be different. In this study $65.1 \%$ of patients were males. Other studies in Indian subcontinent have shown similar results. ${ }^{19}$
Social gender bias in our population might have a contribution to the higher number of male patients admitted to critical care unit.

About $4.36 \%$ of patients actually opted to discontinue treatment or left against medical advice. The majority of patients admitted were from lower socioeconomic backgrounds and the intensive care treatment is exorbitantly expensive. ${ }^{20}$ Being a hospital in the public sector, PICU at TUTH is less expensive than many private hospitals in the country; however, the daily cost of treatment is still much higher compared to the average per capita income of many Nepali families and highlights the need of several types of support systems required for these sick children.

Availability of full-time trained critical care specialists in pediatric ICUs have been shown to improve the quality of care and is also considered to be associated with improved mortality and morbidity indicators. ${ }^{21}$ PICU at TUTH is still developing and is currently run by pediatricians and pediatric nurses who have learned the skills of critical care 'by doing' rather than a formal educational program. There is a large scope for improvement with additional educational opportunities, as is exemplified by increased survival of ARDS and MODS patients in western ICUs. ${ }^{22}$

This was a retrospective study and only those patient characteristics that were available in medical records could be analyzed. Many other patient variables that may be directly linked to patient outcomes could not be analyzed because there were many missing data. This is a major limitation of this study. Patients in this study included the entire spectrum from low to high risk. However, we could not objectively determine the illness severity using severity scoring systems like Pediatric Risk of Mortality (PRISM) and the Pediatric Index of Mortality (PIM) because they were not collected in all patients. Assessment of risk of death at admission is very important in underdeveloped countries with limited resources and few ICUs because it may allow adequate resource planning and also help assess ICU performances across the country.

\section{CONCLUSION}

In conclusion, this study has demonstrated that diverse etiologies of critically ill pediatric patients were admitted to ICU from all over the country. Similar epidemiologic analysis of patients admitted to PICU across the country can serve as a basis for the development of intensive care facilities in the country, developing dedicated protocols for critical care and redistributing the ICUs' available resources for optimal efficiency. 


\section{CONFLICT OF INTEREST}

None declared.

\section{REFERENCES}

1. Saadat S, Cortez R, Voetberg A, Chowdhury S, Sarker I, others. Achieving MDGs 4\&5: Nepal's Progress on Maternal and Child Health. 2014.

2. Ministry of Health and Population, 2019. Annual Report, Department of Health Services 2074/2075 (2017/2018). Kathmandu, Nepal. Ministry of Health and Population, Department of Health Services.

3. Kuruvilla S, Schweitzer J, Bishai D, Chowdhury $S$, Caramani D, Frost $L$, et al. Success factors for reducing maternal and child mortality. Bull World Health Organ. 2014;92:533-44.

4. Pandey KR, Jha AK, Dhungana R, Lamsal R. Health seeking behaviour of parents for children with pneumonia. JNMA J Nepal Med Assoc. 2009;48(174):131-4.

5. Epstein D, Brill JE. A history of pediatric critical care medicine. Pediatr Res. 2005;58(5):987.

6. Acharya SP. Critical care medicine in Nepal: where are we? Int Health. 2013;5(2):92-5.

7. Riviello ED, Letchford S, Achieng L, Newton MW. Critical care in resource-poor settings: lessons learned and future directions. Crit Care Med. 2011;39(4):860-7.

8. Basnet S, Adhikari N, Koirala J. Challenges in setting up pediatric and neonatal intensive care units in a resource-limited country. Pediatrics. 2011;128(4):e986--e992.

9. Khanal A, Sharma A, Basnet S. Current state of pediatric intensive care and high dependency care in Nepal. Pediatr Crit Care Med. 2016;17(11):103240.

10. Ban B, Tuladhar S, Pant S, Sudebi BK. Review of health and health service improvements in Nepal. J Nepal Health Res Counc. 2012;

11. Rosenberg DI, Moss MM, others. Guidelines and levels of care for pediatric intensive care units. Pediatrics. 2004;114(4):1114-25.

12. Basnet S, Shrestha S, Ghimire A, Timila D, Gurung
J, Karki U, et al. Development of a PICU in Nepal: the experience of the first year. Pediatr Crit Care Med. 2014;15(7):e314--e320.

13. Shah GS, Shah BK, Thapa A, Shah L, OP M. Admission Patterns and Outcome in a Pediatric Intensive Care Unit in Nepal. interventions. 2014;4(7):35.

14. Sahoo B, Patnaik S, Mishra R, Jain MK. Morbidity pattern and outcome of children admitted to a paediatric intensive care unit of Eastern India. Int J Contemp Pediatr. 2017;4:486-9.

15. Das I, Bezboruah G, Pathak K. Clinical Profile And Outcome of Patients Admitted In Pediatric Intensive Care Unit of Gauhati Medical College \& Hospital. Infection. 132:16-71.

16. Haque A, Bano S. Clinical profile and outcome in a paediatric intensive care unit in Pakistan. J Coll Physicians Surg Pakistan. 2009;19(8):534.

17. Khan MR, Maheshwari PK, Masood K, Qamar FN, Haque A. Epidemiology and outcome of sepsis in a tertiary care PICU of Pakistan. Indian J Pediatr. 2012;79(11):1454-8.

18. Gupta A, Kapil A, Lodha R, Kabra SK, Sood S, Dhawan B, et al. Burden of healthcare-associated infections in a paediatric intensive care unit of a developing country: a single centre experience using active surveillance. J Hosp Infect. 2011;78(4):323-6.

19. Khilnani $P$, Sharma $D$, Singh $R$, Uttam R, Rajdev $S$, Makkar A, et al. Demographic profile and outcome analysis of a tertiary level pediatric intensive care unit. Apollo Med. 2004;1(2):161-6.

20. Sachdeva RC. Intensive care-a cost effective option for developing countries? Indian J Pediatr. 2001;68(4):339-42.

21. Tarnow-Mordi W, Tucker J, Parry G. Should paediatric intensive care be centralised? Lancet. 1997;350(9070):66-7.

22. Needham DM, Davidson J, Cohen H, Hopkins RO, Weinert $\mathrm{C}$, Wunsch $\mathrm{H}$, et al. Improving long-term outcomes after discharge from intensive care unit: report from a stakeholders' conference. Crit Care Med. 2012;40(2):502-9. 